Originally published in 2008 Inderscience Enterprises Ltd.in the International Journal of Technology, Policy and Management (IJTPM), Vol. 8, No. 2, 2008. DOI: http://dx.doi.org/10.1504/IJTPM.2008.017217 


\title{
Reconfigured domains: alternative pathways for the international wine industry
}

\section{David Aylward*}

Faculty of Humanities and Social Sciences

University of Technology

P.O. Box 123

Broadway NSW 2007, Sydney, Australia

Fax: 02-95142711

E-mail: David.Aylward@uts.edu.au

*Corresponding author

\section{Michael Zanko}

School of Management and Marketing

Faculty of Commerce

University of Wollongong

NSW 2522, Australia

E-mail: mzanko@uow.edu.au

\begin{abstract}
The international wine landscape has undergone dramatic changes over the past 20 years. The two-dimensional wine industry models of the 1980s and 1990s, based on 'national set-perspectives', are failing to address the new and very complex landscape now emerging.

A true globalisation of the wine industry is creating a myriad of challenges and opportunities for multinationals and SME wine firms alike. Most importantly, however, it is creating the need for a significant reconfiguration of national industries to accommodate the internationalisation of production, supply chains, distribution, marketing and consumption.

This paper assesses and comments on these changes within an organisational ecology framework. It compares and contrasts the different organisational structures within New and Old World wine industries, examines their contributions to the internationalised landscape, and proposes alternative pathways within this multidimensional and fluid sector.
\end{abstract}

Keywords: wine industry; organisational ecology; markets; R\&D.

Reference to this paper should be made as follows: Aylward, D. and Zanko, M. (2008) 'Reconfigured domains: alternative pathways for the international wine industry', Int. J. Technology, Policy and Management, Vol. 8, No. 2, pp.148-166.

Biographical notes: David Aylward is a Research Manager for the Faculty of Humanities and Social Sciences at the University of Technology, Sydney and a Research Fellow in the Centre for Governance and Innovation in Business. Aylward has been studying innovation networks, clusters, diffusion and uptake in industry and particularly the wine industry for a number of years. He has written extensively in both scholarly and industry journals and has established a research programme in this area within the Centre for Governance and Innovation in Business. 
Associate Professor Michael Zanko, PhD, is an Associate Dean, Academic Programs in the Faculty of Commerce as well as joint Director of the People and Organization Research Centre at the University of Wollongong, Australia. His current research interests include spatial aspects of interorganisational relations, applied HRM and occupational health and safety management.

\section{Wine's organisational landscapes}

In 2007 the global wine landscape is a very different one from that which shaped production and trade two decades ago. Until the late 1990s the wine sector represented a relatively static, two-dimensional industry model. There was certainly growth, sometimes rapid, and New World producers were emerging from their cottage status, but the supply and demand dimensions remained stable. Wine, embedded within a culture of mystique and somewhat genteel values, was viewed by consumers the world over as something to be taken seriously. It was produced with this same level of respect and acceptance of tradition, and according to organisational scholars, would operate in accordance with an 'organisational set perspective', i.e., a rigidly nationalistic operating paradigm (Aldrich and Whetten, 1981).

There were a limited number of established, affluent markets that producers relied upon to distribute their wine. While revolutionary changes were already taking place in oenological and viticulture research, packaging, transportation and storage, these changes were yet to alter the fundamental dynamics of the industry, although that time was fast approaching. The wine sector was still a traditional primary industry. Domestic markets still absorbed the greater share of production, suppliers and distributors were still largely indigenous to the industry, and family icons still dominated the ownership patterns (Beeston, 1994).

As a result of this relatively uncomplicated landscape, national wine industries, with their respective firms and organisations, arranged themselves within simple operating domains. For Old World industries such as France, Italy, Spain, Germany and Portugal, these domains were an extension of traditional organisational structures. Industries remained highly fragmented with a myriad of tiny family-owned firms sometimes acting individually, sometimes organising themselves into cooperatives for greater market presence. In addition, the organisational domains operated exclusively at the regional and sub-regional level. In many Old World industries the appellation or equivalent system has legitimised these domains and in the process, created strongly branded entities - 'micro climates' of organisation in which a sharp differentiation in approach, the product, and its marketing has enabled these appellations to evolve within a more sophisticated ecological framework (Brook, 2000).

Such entities have, in many respects, worked exceptionally well, despite the over-regulated and inefficient framework in which they operate. Their highly autonomous, regionalised operations have allowed traditional winemaking methods to be complemented by intense vertical integration, localised research and the uninhibited percolation of tacit knowledge. As a result, the 'brand' is not only a natural development, but is embedded within the region's winemaking culture (Sanders, 2005). Organisation within Old World wine industries, therefore, presents an interesting contradiction. Within 
a very formalised and bureaucratic appellation structure, in which each step of the viticulture and oenological process is state-regulated, the wine landscape remains fragmented by informal and very localised production systems. They are systems in which face-to-face contact assumes a key role, as does the terroir and a culture in which not just the product, but its entire life cycle, is woven into the fabric of daily life (Sanders, 2005).

An equally simple, but antithetical, system was bringing success to a number of New World wine industries. These industries, namely South Africa, California, New Zealand and Chile were following Australia's lead in creating a consistent, technically faultless product that was fruit-driven and 'approachable'. In the case of Australia, the product, in fact, was a mirror of its industry - young, brash, and innovative. It was also a product developed within a national framework of industry-sponsored innovation, regulation, distribution, marketing and branding. In order to progress from a rather inconsequential cottage industry of the 1970s and early 1980s industry organisations reconfigured themselves and their agenda to create a national vision of the industry as a 'global player' (Beeston, 1994). This reconfiguration also included the creation of what is possibly the industry's most important entity - the Grape and Wine Research and Development Corporation (GWRDC). Its role, within a new and highly centralised framework, was to set the national Research and Development (R\&D) agenda. Its effectiveness was due to a mandate of R\&D levy collection and distribution. Not only did it establish R\&D priorities for the entire industry, it had the mandated capacity to fund those priorities. Such financial influence ensured that innovation, in the form of national R\&D extension, would provide a foundation for the industry's success at an international level (GWRDC, 2004; Aylward, 2005).

From the closing years of the 20th century, Australian wine would be seen by the world as a national product. It was to be produced primarily at a national level by large companies with vineyards and production facilities in multiple regions. Blending of the product across these regions became commonplace, so much so for example, that a 'Hunter Valley' wine in New South Wales could, in fact, contain blends from the Yarra Valley in Victoria and the Barossa in South Australia. The R\&D supporting that product derived from national institutes based in South Australia, while its distribution was controlled nationally by the Australian Wine Export Council (AWEC), as was its compliance with national standards, its marketing, carried out by the Winemakers' Federation of Australia and its branding, under Brand Australia (Winetitles, 2005). The organisational framework for this product subordinated differentiation to the good of the national agenda. In short, it epitomised an insular 'set perspective'. For the purposes of transforming the industry from its cottage status into one of international recognition, the strategy was very effective. It enabled cohesive planning and execution and more importantly, established Australia's credentials as the producer and exporter of technically faultless, consumer-driven wine that was reasonably priced (GWRDC, 2004).

Other New World industries, watching these developments closely, were now mimicking a number of Australia's strategies. New Zealand, South Africa, Chile and even Argentina were trialing and implementing at least partial versions of the Australian model. California was already progressing down a similar, although more decentralised, path. While both Chile and Argentina were keen followers but plagued by poor infrastructure, New Zealand and South Africa were realising the full benefits of 
the transition. Based on this new organisational structure, the 1990s was to be the decade of New World wine (Aylward and Turpin, 2003; Visser, 2003; Johnson, 2006; Anderson, 2004).

By the turn of the millennium, two orthodox and distinct organisational domains dominated the global wine landscape. There was the fragmented Old World domain, in which thousands of micro and small producers populated strongly branded regions. They competed and cooperated successfully for the dominant share of super-premium and icon price points in world markets, categories for which their differentiated branding provided almost exclusive rights. They also had a strong presence in the domestic and intra-European bulk wine trade. What they did not have was the distribution, volume or marketing capacity to gain any real presence in the substantial popular-premium or commodity wine categories of the US and UK markets. Their tradition and highly regulated structures of production did not allow for this scale of organisation (Brook, 2000; Auriol et al., 2004). These categories were the domain of New World producers whose industries were geared towards the mass production and high volume distribution of the product that Europeans had coveted for so long.

While each organisational domain was still comfortably servicing its primary market categories, subterranean but profound changes in the global landscape would soon highlight their inadequate ecology for addressing new and complex arrangements. This paper assesses these changes within an 'organisational ecology' framework. It compares different organisational structures within existing wine industry models and investigates the challenges they face in adapting to a rapidly evolving environment. The paper contributes to current debate on industry structure by commenting on the current failings, and proposing instead, a multidimensional industry structure using parallel pathways of production, distribution and marketing.

\section{The theoretical context and development}

The strongly emergent globalisation of the wine industry's trade and ownership makes it essential that strategy and operations implemented at national, regional and organisational levels now take account of this globalisation. In many countries, there has been a tendency for national wine industry bodies to adopt, what is referred to by organisational scholars, as an organisation-set perspective in their relationship with the wider industry environment. Based on Evan's (1966) conceptualisation, an organisation set has been defined as “...those organizations with which a focal organization has direct links” (Aldrich and Whetten (1981, p.386). Typically located in an organisation's set would be customers, suppliers, R\&D institutes, competitors, regulators and trade associations.

This particular open-systems perspective draws attention to the embeddedness of organisations within their operational context, to the interdependence between organisations, the potential dependencies and power relations that may arise between organisations, and to a range of adaptation strategies (Pfeffer and Salancik, 1978). However, an organisation-set approach tends to ignore critical relations that take place outside of the focal organisation's immediate domain. Thus, a national wine industry organisation is more likely to be focused on its relations and associated issues with its own national set than those of its global peers, even where the latter may have valuable 
lessons for the former (e.g., knowledge, technology, human) (Narula and Zanfei, 2005). Furthermore, this approach fails to take account of the interactions among set members and their potential significance (Whetten, 1981). For example, there is a tendency by national wine organisations in the New World to under-appreciate the importance of those regional innovation systems operating in Old World industries.

In this paper, we argue that it is more salient to adopt an organisational ecology perspective of national, regional and organisational landscapes in an innovative global wine industry. What is an organisational ecology perspective? 'Organisational ecology' is a term used by different scholars to represent two distinct bodies of research into organisation-environment relations: population ecology and organisational ecology (closely akin to community ecology (Freeman and Audia, 2006)). Population ecology is primarily concerned with the influence of social conditions on the birth, change patterns and death of organisations within populations (Singh and Lumsden, 1990), whereas organisational ecology is more concerned with the patterns of relations that take place between these populations (Astley, 1984; 1985; Trist, 1983). Each also represents a different level of analysis. According to Carroll (1984) population ecology and community ecology (in this case an equivalent of Trist's organisational ecology) are subsets of an organisation that comprises three levels of analysis: organisational, population and community. Each is considered respectively to represent developmental selection and macro evolutionary approaches to societal or organisational evolution. Since the term 'organisational ecology' was first coined by Trist in 1977 and because the bulk of related work is overwhelmingly within a population ecology framework (Aldrich, 1999; Hannan and Freeman, 1989), this paper uses a definition of organisational ecology broadly in line with Trist's formulation.

Based on the work of Emery and Trist (1973) and Trist (1977; 1983) and then developed subsequently by others: Astley (1984; 1985), Astley and Fombrun (1983), organisational ecology has been referred to as "...the organizational field created by a number of organizations whose interrelations comprise a system at the level of the field" (Trist, 1977, p.162). The fields or interorganisational domains are "functional social systems that occupy a position in social space between the society as a whole and the single organization" (Trist, 1983, p.270). Thus organisational and interorganisational activities and outcomes, according to this model, are analysed not at the individual level but at the level of larger systems within which individual organisations reside (Trist, 1977, p.167). This, in effect, is a figure ground reversal. Attention directed at inteorganisational systems within an organisational ecology approach holds that in addition to competition and conflict between constituents, there are important collective and cooperative forces that facilitate systematic adaptation to the environment. Overarching collective adaptation to turbulent environments increasingly characterises contemporary society. From an organisational ecology perspective, such adaptation is consciously proactive in that it recognises and advocates that groups of like and unlike organisations can work to shape their environments and futures. In this sense, organisations are seen to be active players in their environment rather than external to that environment.

The 'organisational ecology' perspective provides a suitable and potent context for the study's analysis of structural change within this global wine industry. First, it emphasises the connections that take place between organisations within the defined community, in this case the global wine industry. Clearly, explanations about behavioural 
and structural phenomena at this level will need to draw upon explanations about the actors and social forces involved at succeeding lower levels (national, regional and organisational). Secondly, this perspective invokes process and structural explanations about the significance of life in a global wine community. Therefore, the organisational ecology model overcomes the notion of the environment as some exogenous constraint. Rather, organisations constitute and are constituted by their environments.

Thirdly, this community model puts the 'egocentric orientation' (Astley, 1984) of much of the business policy and corporate strategy literature into a more balanced perspective. Namely, it suggests that strategic choice independent of other organisations is impossible, since their mere existence brings organisations into contact with one another. Fourth, the organisational ecology model highlights the weakness of single organisation solution-seeking to problems in turbulent environments that require collective, multi-party actions. The nature of the organisational ecology model overcomes this by its focal shift to the connected, interorganisational global field.

Finally, this model not only addresses domain-based (for example, global wine industry) issues but also serves to maintain close contact with the extended social field (Trist, 1983), in effect the global wine industry's environment, as well as the 'figure' (for example, the national wine industry, the regional wine cluster, the wine firm). An organisation (community) ecology approach to any analysis of the global wine industry will facilitate a clearer reconciliation between what Bathelt et al. (2004) refer to as "local buzz and global pipelines", the intimate connection between regional production sites and global distribution (Asheim and Gertler, 2005, p.310). In fact, it unpacks the current notion of dual, local/non-local geographies into more germane organisational, regional, national and global geographies.

\subsection{Theoretical lessons}

In applying the organisational ecology theory to a sector such as the global wine industry, this paper extends the conceptual map of domains and actors beyond localised and national settings and highlights the elasticity of the ecological framework. In fact, it is this elasticity that lends value to theory development.

The concept's elasticity is essential in providing analytical linkages between local portals of wine production within endogenous communities and their connection to the global pipelines of distribution, marketing and consumption. It allows for a greater understanding of the interactions along their supply chain and how those interactions are effected by oscillations across the international supply and demand curve. Further, by extending an understanding from national to global frameworks in which a community of actors is puncturing traditional boundaries of behaviour, the organisational ecology concept allows for a greater articulation between empirical and theoretical domains.

The global wine industry's multidimensional landscape also provides a unique testing ground for the adaptive nature of this framework. In a sense, this paper is reporting on the applicability of a multidimensional industry environment to what is still an emergent theory. What we find is that, unlike a population ecology model in which the explanation of activity is artificially confined to somewhat insular communities, the organisational ecology framework is represented in the transient contours of the global wine trade. It is a transience that is sophisticated rather than fickle and as such, requires an equal level of sophistication and adaptability from each organisational level of subscription. 
The practical implications of these contours can only be understood and explained by a conceptual framework that recognises differentiated environments and the intricate connections between those environments.

\section{Ecology of the global wine industry}

This paper exposes the emergence of two distinct sectors within the global wine industry. These emerging sectors - the commodity wine industry and the fine wine industry represent a distinct break with the two-dimensional model of the 1970s and 1980s. They represent what could prove to be two parallel and robust sectors operating in a complementary fashion. Currently, however, their emergence signifies a nascent reconfiguration of once-'given' operating domains. As this emergence continues we should see a further consolidation of the commodity wine sector across New and Old World industries alike, while witnessing a migration of fine wine recognition and status from Old to New World industries.

In organisational terms, the implications of such developments are profound. It means highly differentiated, single-vineyard management rather than multi-region, standardised plantings. It means small crop production, hand-picking, and basket-pressing rather than mass production, mechanical harvesting and steel presses. There will be 24 hour monitoring of the maturation process before ageing in the best French oak barrels, rather standard maturation followed by fermentation in steel tanks with added oak chips. The end product would be a hand-crafted, subtle and finely balanced wine of distinction rather than a pleasant, mass-produced and ultimately bland product with no heritage.

Perhaps most importantly, the product could be traced to a single vineyard in a single region, with a particular type of soil, climate and wine-making techniques, or, as the French would say, terroir. Such a product, region and wine-maker would be catering not to generic national guidelines for a label such as Brand Australia, but to global distribution points in which the product's heritage and its 'story' are critical to a final, successful sale. This level of multipoint differentiation, where local portals of production actually bypass national industries to supply discerning international markets is the template for a fine wine sector. It is also a template and a practical explanation of organisational ecology in action. The current differentiation emerging within the wine industry emphasises a need for explanation and analysis through a community-based prism. It is a prism that reflects not simply the national operating boundaries and immediate supply chain neighbourhoods, but one that in fact magnifies the prism's refractive qualities. This level of differentiation sheds light on the strange yet effective nexus of global and local industry priorities that demand an adaptive theory with the elasticity required for multidirectional growth. It also provides the practical 'stepping stones' of understanding required in extending traditional ecological frameworks into a global, multilayered arena.

\section{An emerging and complex consumer landscape}

The differentiation is also reflected in the escalation of mergers and acquisitions between international wine groups over the past decade, in particular, which has created multiple supply and demand channels. These channels allow and even encourage geographically 
remote production and distribution points across the globe. For example, a recent initiative by one of the world's largest wine firms provides for the production of a single brand on two or even three different continents, with localised labelling and identity, but global distribution and marketing. The product will contain the same grape varieties, but will be blended from different regions across different continents. Its labelling will reflect the diversity of these regions and pay homage to local heritage. However, such differentiation will still be subsumed within a single global brand.

Other conglomerates such as Constellation Wines operate in an altogether different, but still global manner. Constellation's current portfolio of wine companies includes Australia's largest winemaker - BRL Hardy, California's iconic Mondavi Wines, Italy's largest firm - Ruffino Wines and Canada's own Vincor. Although the ownership is centralised, Constellation's strategy has been to provide these individual firms with a relatively autonomous operating environment. The firms retain their own brand, their own marketing and, to some degree, the authenticity of local production systems. Distribution, human resources and profit margins, however, are viewed increasingly within a global framework (Sands, 2006).

For the uneducated consumer, this landscape is not only complex, but also complicated. For example, a purchase of 'commodity' style wine from one of the oldest and most respected wineries in South Australia - Tintara Wines - would in fact be a purchase from Australia's giant BRL Hardy with the profits being returned to Constellation Wines in the USA. Similarly, a purchase of Montrose from the small region of Mudgee in New South Wales would be a purchase from the giant Orlando-Wyndam with profits flowing back to France's Pernod Ricard.

The new landscape that consumers are now forced to traverse is one dominated by the wine industry's multinationals, but as yet they do not monopolise it. Further complicating the landscape is the myriad of micro and SME wine firms that have also reoriented their focus from domestic to international markets and compete for market share across all price-points. There exists an almost schizophrenic selling environment. Markets such as the UK, USA, Scandinavia, Germany, Canada and Japan are being saturated with products ranging from commodity-style, standardised blends through an entire spectrum of quality to the fine wines, where competition is intense between hedonistic 'Parker' styles and the subtle elegance of French 'first growths' (Faith, 2002; Aylward, 2006a).

\section{Production landscapes and the dilemma for national industries}

The production landscape is as complex as the one that consumers must now navigate. As already noted, there are the vast production facilities that form part of multinational firms' global portfolios. These are dedicated to mass-produced products developed for immediate consumption. The products are almost always blended from multiple regions and provide excellent value for money, but are largely indistinguishable from those of their competitors. The target market includes the popular-premium price points (USD\$6-12), which are dominated by the 'occasional drinker' with little knowledge of, or interest in, the product's making, heritage or region. Competition between producers is based almost exclusively on price, in what Croser (2004) refers to as 'a race to the bottom'. This popular-premium section of the market is where the main revenue is generated, but profit margins are small, hence the need for large volumes. It is a section 
that also requires high capital investment for standardisation of production lines, substantial market presence for the purchase of supermarket shelf space, and efficient and flexible distribution channels. For these reasons alone, this sector is heavily populated by the industry's multinationals. Because multinationals are so central to the economic success of their host industries, it is also a sector that tends to capture the imagination and policy orientation of national wine industries (Aylward, 2006b).

After more than two decades of these multinationals creating superior export pathways, the 'democratisation' of international markets has also attracted the New World's boutique, small and medium wine firms. Traditionally focused on developing small-batch products that embrace their region's characters and target a committed clientele, many of these firms are now attempting to compete in the 'generic' popular-premium segments. To do so, they are often forced to dramatically increase production, supplement their own grape supply with other, often inferior supplies, and of course, revise their wine-making practices to accommodate a different consumer bracket with a different taste. Particularly in the current climate of product surplus, many argue that they are competing increasingly less on product quality and adhering instead, to the price competition of their larger peers (Bailey, 2006; Lockshin, 2006; MacQuitty, 2006).

In the majority of cases these smaller firms are failing in this realignment. In New World industries where superior distribution channels have already been established and where export-orientation is virtually a pre-requisite to success, these small firms still struggle to make the transition. Among Old World industries that lack the infrastructure, distribution channels and acceptance of the product as a tradable commodity, the failure rate is proving unacceptably high. The 'all things to all people' approach being adopted by these small firms has, in many cases, resulted in their traditionally successful bases being sacrificed to the pursuit of a market segment for which they are simply not equipped to compete.

Risks associated with this organisational restructuring are possibly most acute among the tiny, family wine operators of France and parts of Italy. For generations these micro-businesses have occupied a legitimate role within the closely knit fabric of their community and the broader wine landscape. They have symbolised a seamless blending of art and science, with small-batch production of a highly localised and differentiated product that primarily satisfies the needs of the local community and only then is distributed to a broader consumer base. Only their surplus product has undergone any real 'commodification' through its supply to local cooperatives and the consequent blending of generic, generally low-quality products. It has been these cooperatives that have traditionally provided the only viable export channel for the micro-businesses with their critical mass and greater distribution leverage (Echikson, 2004; Steinberger, 2004; Ambergey et al., 1993).

The reconfiguration of the international landscape, however, with its demand for 'approachable' wines across multiple price-points, has ensured a severe 'identity crisis' among many Old World micro-businesses. No longer satisfied with the generic, low-quality product of their cooperatives, markets are instead demanding a technically faultless, consumer-driven product that these businesses lack the capacity to supply. They do not have the technology, distribution channels, production lines or financial resources to ensure either a constant supply to these markets or the essential shelf-space within the super or hyper-retail outlets. Neither do they have the export culture of the New World's 'born exporters' and therefore lack the knowledge and flexibility required by a constantly changing marketplace. Perhaps most importantly and due largely to their highly localised 
production culture, they lack a cohesive $R \& D$ framework. There is little capacity, therefore, for implementing uniform change within the R\&D that underlies their products and upon which an adaptable market response depends. In their current organisational environment, it is this lack of an effective framework that is critical to their deteriorating potential (Echikson, 2004; Brook, 2000).

\section{$6 \quad$ An ideal landscape for multinationals?}

Contrary to the common portrayal of multinationals as the ultimate benefactors of an homogenised system, they too are finding difficulty in navigating the new landscape. Their main revenue (but rather less profit) is derived from the bulk and popular-premium (USD\$3-\$12) segments of the market. These are also the segments that provide the most intense price competition, so there is little opportunity to deviate from the standardised product demanded by consumers at these price-points. As a result, the multinationals' own R\&D frameworks, marketing and distribution channels are increasingly tailored towards the constant supply of consistent, but ultimately character-free, wine style (Henry, 2006).

There are two critical consequences of such a focus. The first is that the multinationals' reputation for producing anything other than a homeless and rather bland product is being steadily eroded. The conglomerates of the wine world are being irrevocably linked to the product's commodification, or as many critics now claim, 'coca-colarisation' (Interviews, 2006). Despite the fact that a number of these conglomerates also produce some of the world's finest wine, the popular-premium segments of the market and the consumer tastes that populate these segments have become so pervasive that reputations are being captured by this category. The resources, the distribution, the retailing and the pure financial impact of this mass-produced product in the world's largest markets are, to a large extent, negating these same firms' reputation for differentiation. They have introduced coca-colarisation to the wine world and are now finding it increasingly difficult to remove its shadow from their brands (Aylward, 2006b; Croser, 2006).

Second, as consumer, producer and industry support for the popular-premium product grows, the fine wine segments of the market are being neglected. Human and technological resources are being increasingly re-directed towards those sections of the market that are perceived to require them most. Large-scale vineyard management, bottling and other production lines, marketing, distribution, export promotion and retail sales in these sectors of the market display the same characteristics and requirements as any commodity-style production system.

\section{The R\&D landscape}

The momentum of such systems also creates domino effects. The bulk and popular-premium wine markets of 2006, with their demand for standardised products, have been largely responsible for the lack of contours within the industry's R\&D landscape. This is particularly the case among New World producers with highly centralised structures and nationally mandated policies. In Australia and South Africa, for example, the national wine industries have incorporated central intermediary 
organisations whose mandate is to represent the national industry. Whether they are lobbying associations, regulators, export councils or R\&D organisations, their responsibility extends across the entire industry and their funding is typically derived from the firms themselves, with partial or full matching funds from government. Because firm contribution is often based on a levy system, it increases in accordance with the size of the firm and its production. It is not too cynical, therefore, to suggest that the interests of the largest firms correlate quite closely with those of the industry organisations. Simple economic models dictate that national R\&D landscapes are being configured to reflect the requirements of their largest multinationals. In organisational terms, this means that the supply of $R \& D$ is necessarily generic in nature, is often linked to a national marketing strategy and services those products with the highest sales volume (Smart, 2005; Aylward, 2006b).

Among New World industries, the Australian R\&D landscape epitomises this model. Since the early 1990s wine R\&D in Australia has been managed by the Grape and Wine Research and Development Corporation (GWRDC), whose role has been the collection of R\&D dollars, the implementation of research priorities and the distribution of funds (GWRDC, 2005). Working in concert with the Australian Wine Research Institute (AWRI) and the Cooperative Centre for Viticulture (CRCV), this institute has helped nationalise the $\mathrm{R} \& \mathrm{D}$ agenda. Through bodies such as the Australian Winemakers' Federation they have also worked to link the agenda seamlessly with the industry's perennial marketing strategy - that of 'Brand Australia'. Both approaches are directed towards a single goal - selling as much Australian wine to the world as possible. The goal is being fulfilled. In 2007, more Australian wine than ever before is being exported. In the world's largest market - the USA - Australia has overtaken France and Italy as the largest supplier. Currently, seven of the top ten brands in the UK are Australian.

There is no question of the Australian wine industry's ability to export large volumes. There are serious concerns however, over its increasing inability or will to differentiate within this volume. It could be argued that R\&D, led by multinationals within Australia and other New World industries, is contributing to an organisational landscape in which 'the lowest common denominator' has become the new benchmark. By linking the R\&D approach with strategies such as 'Brand Australia', the industry is also convincing the world's consumers that all its wine 'comes from the same barrel' in an amorphous region by the name of South Eastern Australia. As such, it remains as undifferentiated as any other commodity drink in the market. Margan (2006) from Australia's Margan Family Wines emphasised this point at a recent national innovation meeting when he stated that "Our marketing to date has been too generic....The gatekeepers are bored to tears with Brand Australia and we're going to lose them if something doesn't happen in the next 24 months". The fact that export volumes are at historic highs while export value per litre is consistently falling certainly indicates that 'Brand Australia' and 'differentiation' remain at opposite ends of the consumer spectrum.

\section{$8 \quad R \& D$ as a trigger for change?}

Organisational scientists might well describe the New World R\&D/marketing paradigm as one of inertia (DiMaggio and Powell, 1991; Hannan and Freeman, 1989). The strategy that proved so successful in the 1980s and 1990s, when the wine landscape was a far less cluttered one and New World industries fought for global recognition, is now rapidly 
approaching obsolescence. Yet industries that have built future strategies on past success are reluctant to undertake meaningful reconfiguration. It is a situation common to any industry sector that has evolved within a dominant and previously successful framework. It is also one that classical theorists such as Hannan and Freeman (1984) refer to as 'organisational inertia' or 'lock-in'. According to such a theory historically successful pathways of organisation and innovation become entrenched and DESPITE minor adaptation, these pathways create barriers to alternative approaches. Organisations, in particular, tend to be risk-averse and opt for short-term safety rather than longer-term potential. Because R\&D within New World industries has been configured within a largely centralised framework, these pathways have become unusually rigid (Ruef, 2004; Hannan et al., 2004). It is widely recognised within the Australian and South African wine industries, for example, that the production and marketing landscapes are undergoing radical reconfiguration and traditional $\mathrm{R} \& \mathrm{D}$ /organisational frameworks are no longer appropriate. Yet it appears that decision-making boards, heavily influenced by multinational membership, remain locked-in to the illusory safety of a simpler, more understandable paradigm. The focus appears to be on immediate revenue returns rather than the sustainable returns of industry-building, reputation and ultimately economic health.

However, just as the R\&D framework has provided a foundation for what DiMaggio and Powell (1991) might term the 'iron cage' of inertia, it also has the potential to create more flexible pathways. In fact, amidst one of the world's oldest and most 'inertia-prone' wine industries, the alternative pathway phenomenon is currently revolutionising wine production. France, with its somewhat archaic AOC system of wine regulation, is widely criticised as resisting organisational change and refusing to recognise innovative approaches (Brook, 2000; Echikson, 2004; Auriol et al., 2004). Yet a new wave of highly innovative and successful production is emerging from within this 'inertial' domain's most sacred of wine regions - Bordeaux. While wine critics across the globe consider Bordeaux to embody the most traditional of Old World wine practices, it has, in fact, been at the forefront of a number of wine revolutions throughout history. The current winemaking phenomenon again highlights this region's ability to adopt radical changes (Campbell, 2004).

\section{Lessons from Bordeaux}

At the turn of the millennium a common perception was that the international wine world was divided into two opposing forces. The New World was sacrificing heritage, terroir, regionality and traditional production methods for innovation at every step of the supply chain. Giant vineyards in multiple regions rather than small family plots, mechanical harvesting rather than hand-picking, mechanical grape sorting rather than hand sorting, oak chips in metal tanks rather than aged oak barrels and a technically flawless product rather than one determined by the vagaries of season characterised the New World philosophy (Brook, 2000; Johnson, 2006).

The Old World was perceived, often correctly, as rejecting these innovations and representing everything that was antithetical to the philosophy behind them. Old World industries such as those in France, Italy, Spain and Portugal were perceived by many as belonging to a quaint, small-scale system that was being left behind by the multinationals and their New World host industries. Yet within this 'small-scale' system, R\&D was to 
emerge as the trigger for change. While New World operators were enlarging their scale across the supply chain, a new group of Bordeaux winemakers was creating synergies between New World innovation and Old World techniques.

The garagistes, as they are now commonly known, represent a new breed of winemaker in France. Producing their small-batch wines in simple, garage-style premises, from which the name is derived, attention is focused exclusively on producing the best possible wine, regardless of cost. The philosophy behind this approach dictates that there is always a market for fine wines and that this market is largely immune to oversupply. The mechanism behind the approach has been the synergy of Old World hand-crafted practices with the unapologetic application of New World innovations. The growing, irrigation, soil management, distilling, maceration, temperature control, and ageing of their product benefit from the widespread application of Californian and Australian technological breakthroughs. As a result, like its New World counterparts, the product is no longer prone to faults 'beyond the winemaker's control' (Echikson, 2004).

This is where the similarities appear to end. These state-of-the-art technologies have been applied not to the large-scale production of multinationals, but to micro operations, where attention to detail is absolute. These operators do not hesitate in applying mechanisation where it is most beneficial, but human intervention plays a critical role. This is controversially referred to as the 'human element of terroir'. From planting on specially selected and cultivated micro-blocks of one or two acres, to over-pruning, hand picking after an extended ripening period, hand sorting of individual grapes rather than bunches, constant attention and revision within the actual winemaking process, and ageing in up to $200 \%$ French oak (where the product is transferred between barrels), the garagistes are realising the potential of selective and flexible R\&D (Steinberger, 2004; Campbell, 2004).

The success of these garagistes is amplified by the cultural framework within the Bordeaux wine industry. Their micro plantations, small-batch production, hand-crafting, and minute attention to detail provide for the foundation of their success, but the cultural parameters within which they operate nurture, rather than inhibit such practices. There is no centralised R\&D agenda. There is no national branding approach or entrenched domains of mass production. Ultimately, there is no levelling of the wine landscape's more 'noticeable' contours. Rather, there is an almost intense legitimisation of regional identities that punctuate this landscape and ensure that standardisation is prevented. Further, there is an inherent understanding that regions are different, with different climates, different cultures, different soils and very different approaches. The R\&D, although not on a scale of organisation such as is evident in many New World industries, can be more readily tailored to the requirements of a particular region and its product. As a result, we are witnessing the rise of a new class of winemakers that in other wine industries is represented only by culturally isolated individuals (Auriol et al., 2004; Echikson, 2004).

The apparent logic of this success is that in 2006, amidst a global wine glut, these garagistes could not meet the demand for their product, almost regardless of the prices they charged. Each individual may produce up to six thousand cases with per-bottle prices approaching $\$ 1,000$. Their product is most commonly sold to negociants as futures, while still maturing in the barrel, two or even three years before it will be distributed to retailers. The producer's meticulous hand-crafting is recognised by its consumers. They are prepared to pay for what they consider a unique, unsanitised 'story'. 


\section{Differentiated organisation}

Most wine observers, and in fact, wine producers, view their industry as a single entity. It is an entity that stretches across multiple price points, varieties, wine styles, production methods and consumers. It is also an entity that, at present, is struggling with this stretch. With the current glut, price-points across all markets are being reduced to accommodate excess stock. The lack of distinction within this single entity will ensure that 'the race to the bottom' continues as long as there are too many wineries producing too much wine. The short-term beneficiaries, of course, are the consumers. Over the longer term, however, the economic health of the industry may be in jeopardy. While the industry's organisational domains are reconfigured to cater to the popular-premium (A $\$ 10-\$ 15)$ market, commodification of the product is becoming more entrenched. Margins are being further reduced and all but the largest wine firms are experiencing financial hardship.

Perhaps, therefore, the most notable aspect of the garagiste phenomenon is the organisational distinction that it has brought to the wine industry. It has done this in several ways. First, it has reignited the acceptance of fine wine among markets beyond those of the rather exclusive First Growths (the aristocratic chateaux of Margeaux, Latour, Rothchilds and Haut Brion, for example). Within small-scale, unpretentious production sites, garagistes have created wines that compete directly with their more traditional 'Left Bank' cousins. They have demonstrated clearly that the fine wine markets of the world need not be the domain of ancient chateaux controlled by aristocratic families. This very fact has revolutionised the Bordeaux wine industry. It has also ensured that fine wines are no longer decided by heritage alone (Johnson, 2006; Campbell, 2004).

Second, the fact that this garagiste movement evolved and has become an acceptable, even enshrined practice in one of the world's most traditional wine industries - Bordeaux - has created a legitimate entrée for its sanctioning within New and Old World industries alike. Leading New World industries such as California and Australia are yet to learn from the French example. In Australia particularly, iconic producers such as Cullen's and Vasse Felix in Western Australia, Henschke and Petaluma in South Australia or Lake's Folly in New South Wales remain isolated as fine wine leaders within what many producers argue is an uninspired industry (Aylward, 2006b). There are increasing numbers of boutique and SME producers following the iconic lead. They are focusing on the development of single-vineyard varieties, basket-pressing, and minimal filtration (rather than the New World custom of heavy and regular filtration that efficiently removes character from the wine). The resulting products are captivating the judges and raising individual and regional reputations. But these producers are succeeding despite the organisational framework of their host industry, not because of it. In terms of resources, marketing, R\&D and industry support programmes, they claim they are largely ignored (Smart, 2005; Croser, 2006; Aylward, 2006b).

Other New World industries, however, such as those of New Zealand, and to some extent Chile, are recognising the value of a nurtured fine wine industry. Chile has long maintained a practice of adopting complementary Old and New World practices. As such, it has attempted to introduce (with mixed success) New World technological practices while conserving a differentiated approach to production and branding. New Zealand recognised early that it could never compete internationally in terms of volume and therefore chose very distinctive organisational pathways. These pathways involved a centralised approach to industry representation and promotion and even an 
Australian-inspired knowledge diffusion network, but highly differentiated production and branding based on strong regional identity. The New Zealand industry is conscious of the domestic and international market value placed on a point-of-difference. As a result, regions such as Marlborough follow the 'walled city' approach of California's Napa Valley. In other words, regional recognition is promoted before national branding to an extent that there is an active pursuit of distinction. The approach ensures that geographically proximate regions are perceived, by producers and consumers alike, as culturally removed from the region in question (Smart, 2005).

New Zealand's R\&D system underpins this differentiated approach by the placement of region-specific R\&D officers. In the case of Marlborough, there are even 'regional cluster' officers whose responsibility it is to develop the natural supply chain strengths, horizontal integration and general knowledge diffusion of the area. These seemingly subterranean initiatives actually exert substantial influence on the branding capacity of a region. In the case of Marlborough, the branding provides an effective entrée into the world's iconic and super-premium price-points (Smart, 2006).

\section{Restructuring organisational domains}

Finally, organisational distinction within both these initiatives has demonstrated the viability of two separate wine industries - the commodity wine industry and the fine wine industry. It has also demonstrated the need for a conceptual reconfiguration among industry decision-makers. Leading wine thinkers such as Australia's Croser (2004; 2006) and Pirie (2006) continually highlight the need to conceptualise, resource and market the wine industry as two distinct entities. They argue that there is clearly a role for the commodity industry; that multinationals do and possibly should dominate this sector, and that there will always be demand for the product. Dividing the industry into two distinct entities should not be seen as an attempt to undermine or de-emphasise this sector. It should, however, be acknowledged as the institutionalisation of a requisite and legitimate parallel pathway. Henry (2006), a recent appointment at the Australian Wine and Brandy Corporation, reinforces these sentiments when speaking of the need for regionality and industry support for fine wines. Perhaps, however, Johnson (2006) puts the product divide most simply when stating that:

At one extreme you have something no more interesting than lemonade: perfectly swallowable but equally forgettable. At the other a convulsive, electrifying, high-tension display: charisma in a bottle.

Yet in Australia, thinkers such as Croser, Pirie and Henry represent a notable minority among industry leaders. While the above notion is accepted in 'traditional' regions such as Bordeaux, it is seen as almost revolutionary in Australia 'innovative' industry. There appears to be little understanding that an industry's iconic and fine wine producers provide a reputation of quality that benefits the entire sector. Reputation, although not tangible in terms of financial return, provides possibly a far greater long-term return. This 'reputation-making' strategy is certainly evident in France's Bordeaux region, which is known internationally as producing the world's finest wine. The irony is that of Bordeaux's 20000 producers, less than 60 are AOC classified and produce wines in the icon price points. The remaining producers create often mediocre products 
that sell in the popular-premium and bulk wine price points (between USD\$1-\$6 per litre). Yet it is the 60 AOC producers that have given Bordeaux its fine wine reputation (Echikson, 2004).

\section{Future pathways}

The new contours being created by the garagiste and similar movements have the potential to add definition and choice to what has been a somewhat ambiguous offering. But the potential depends heavily upon industries' ability to identify and understand the shifting characteristics of these 'contours' and provide the differentiated support they require. The key to any new wine industry model will remain an acceptance of differentiation. This will apply to vineyard selection, harvesting, maturation, ageing, branding, marketing and distribution. It will mean the parallel support of blended, multiregion, commodity-style wine alongside hand-crafted, region-specific, iconic wine. And ultimately, this parallel system should come to represent the evolution of a global industry capable of responding to a myriad of consumer choices and punctuated by the production sites that cater to those choices.

The theory behind this differentiation is identical for Old and New World industries alike. The application, however, is at opposite ends of the spectrum. For most Old World industries the emphasis will need to be oriented towards competitive production cooperatives, varietal branding, state-sponsored $\mathrm{R} \& \mathrm{D}$ and efficient distribution systems. These initiatives would at least partially address the unsuccessful attempts at developing viable commodity wine markets. The strong focus on regionality, the family-dominated production landscapes, the rigid system of regulation and the relative lack of coordination in R\&D has ensured that what has worked in favour of fine wine production and sales, has effectively undermined any articulation into the world's popular-premium markets. There has been a distinct unwillingness to develop complementary but larger-scale pathways of production and distribution and an apparent reluctance to adopt those innovation systems that have enabled success among New World industries in these price-points. The organisational domains of most Old World industries remain fragmented and as such, provide little potential for change at the regional level. Only through coordinated state resourcing can these Old World industries develop and sustain the strong branding that has allowed the makers of Jacob's Creek and Yellow Tail to dominate the commodity price-points. But the potential is certainly there for parallel systems of production that rely on different vineyard management, different R\&D extension and different distribution systems in order to serve different purposes. In short, there is the potential to dismantle the 'organisational set perspective' of national legacies.

For the New World, the challenges are just as great. As mentioned previously, New World wine growing, production, distribution, and branding is highly innovative in a technical sense. Primarily, it is oriented towards the efficient, large-scale supply of a product that is blended from multiple regions. It is also a product that is mass-produced, technically faultless, heavily synthesised, fruit-filled, high in alcohol and many argue, character-free. The New World product has been enormously successful in the commodity markets of the world, where a pleasant and unsurprising beverage is in considerable demand. The scientific approach adopted by Australia, South Africa and California provides the R\&D that underpins this capacity. The overriding pursuit of technically faultless wine within these industries, however, was also to be a major 
contributor to what many describe as their products' character-free qualities. Increased use of irrigation, universal blending, over-filtration to remove unwanted 'characters' and multiple additives created a clean but bland product.

What is needed in these particular industries is an understanding and appreciation of the changing international wine landscape. The organisational pathways that brought so much success throughout the latter part of the twentieth century are now amplifying the challenges of a globalised, and very complex industry. Ecological frameworks must be adapted and, in the case of R\&D, central bodies such as South Africa's Nietvoobij Institute for Viticulture and Oenology and Australia's GWRDC can no longer rely on prefabricated mandates serving national agendas. Instead, New World industries will need to escape the inertial paradigm of their once-successful pathways and adopt differentiated models of region-specific R\&D nodes. As viable and well-resourced extensions of the central R\&D bodies, such nodes would cater to individual regions, respond to regional $R \& D$ requirements, directly involve the region's stakeholders in decision-making and underpin the region's own unique approach. They also appear to be the only practical way of supporting region-specific, differentiated products in parallel with the already well-resourced commodity sector.

The existing organisational ecology of vineyard management, large-scale production lines and volume-dependent distribution channels remains critical to commodity style products. But it can no longer be focused on a single community. Industry leaders in the New World must heed the Bordeaux lesson. They must understand that 'reputation' percolates throughout an entire industry. Support for iconic and super-premium producers, support for regional boutiques and support for alternative innovation pathways are necessary components of a sophisticated wine industry.

\section{Concluding remarks}

These pathway descriptions should in no way be read as a simple recipe for success. Rather, they are intended to illustrate the complexity of the current international wine industry and the need frame its analysis within an organisational ecology context. In both New and Old World industries there remain structural legacies or inertial domains that have been retained at the expense of the industry's adaptation. Such structures are no longer the symbols of successful two-dimensional pathways. Rather, they should be viewed as the foundations from which to reconfigure ecological frameworks in industries that no longer operate within national parameters but are part of a global and fluid organisational community.

\section{References}

Aldrich, H.E. (1999) Organizations Evolving, London: Sage.

Aldrich, H.E. and Whetten, D.A. (1981) 'Organization - sets, action-sets and networks: making the most of simplicity', in P. Nystrom and W.M. Starbuck (Eds.) Handbook of Organizational Design, Oxford: Oxford University Press, Vol. 1, pp.285-408.

Ambergey, T.M., Kelly, D. and Barnett, W. (1993) 'Resetting the clock: the dynamics of organizational change and failure’, Administrative Science Quarterly, Vol. 38, pp.51-65.

Anderson, K. (Ed.) (2004) The World's Wine Markets: Globalization at Work, United Kingdom: Edward Elgar, p.276. 
Asheim, B.T. and Gertler, M.S. (2005) 'The geography of innovation: regional innovation systems', in J. Fagerberg, D.C. Mowery and R.R. Nelson (Eds.) The Oxford Handbook of Innovation, Oxford: Oxford University Press, pp.291-317.

Astley, W.G. (1984) 'Toward an appreciation of collective strategy', Academy of Management Review, Vol. 9, pp.526-535.

Astley, W.G. (1985) 'The two ecologies: population and community perspectives in organizational evolution', Administrative Science Quarterly, Vol. 30, pp.224-241.

Astley, W.G. and Fombrun, C.J. (1983) 'Collective strategy: social ecology of organizational environments’, Academy of Management Review, Vol. 8, pp.576-587.

Auriol, E., Lesourd, J-B. and Schilizzi, S.G.M. (2004) The World's Wine Markets: Globalization at Work, in K. Anderson (Ed.), United Kingdom: Edward Elgar, pp.59-68.

Aylward, D. (2005) 'Global landscapes: a speculative assessment of emerging organizational structures within the international wine industry’, Prometheus, Vol. 23, No. 4, pp.421-436.

Aylward, D. (2006a) 'Global pipelines: profiling successful SME exporters within the Australian wine industry’, International Journal of Technology, Policy and Management, Vol. 6, No. 1.

Aylward, D. (2006b) 'Innovation lock-in: unlocking research and development path dependency in the Australian wine industry’, Strategic Change, Vol. 15, pp.361-372.

Aylward, D. and Turpin, T. (2003) 'New wine in old bottles: a case study of innovation territories in new world wine production', International Journal of Innovation Management, Vol. 7, No. 4, pp.501-525.

Bailey, P. (2006) ‘Bulking up’, Wine Business Monthly, Adelaide, August, pp.30-33.

Bathelt, H., Malmberg, A. and Maskell, P. (2004) 'Clusters and knowledge: local buzz, global pipelines and the process of knowledge creation', found in B.T. Asheim and M.S. Gertler (2005) 'The geography of innovation: regional innovation systems', in J. Fagerberg, D.C. Mowery and R.R. Nelson (Eds.) The Oxford Handbook of Innovation, Oxford: Oxford University Press, pp. 291-317.

Beeston, J. (1994) A Concise History of Australian Wine, London: Allen \& Unwin, pp.4, 135, 233.

Brook, S. (Ed.) (2000) A Century of Wine: The Story of a Wine Revolution, London: Octopus Publishing Group, pp.24-46.

Campbell, A. (2004) 'Backyard wineries and garagistes', Small Business Trends, http://www.smallbiztrends.com/2004/11/backyard-wineries-and-garagistes.html.

Carroll, G.R. (1984) ‘Organizational ecology’, Annual Review of Sociology, Vol. 10, pp.71-79.

Croser, B. (2004) 'Brand or authenticity?’, Australian \& New Zealand Wine Industry Journal, pp.12-22.

Croser, B. (2006) 'Waxing and whining', Masters of Wine Conference, Napa Valley, June.

DiMaggio, P. and Powell, W. (1991) 'The iron cage revisited: institutional isomorphism and collective rationality in organizational fields', in P. DiMaggio and W. Powell (Eds.) The New Institutionalism in Organizational Analysis, Chicago: The University of Chicago Press.

Echikson, W. (2004) Noble Rot: A Bordeaux Wine, WW Norton \& Co. Britain, pp.176-190.

Emery, F.E. and Trist, E.L. (1973) Towards a Social Ecology, London: Plenum Publishing Company.

Evan, W.M. (1966) 'The organization set: towards a theory of interorganizational relations', in J.D. Thompson (Ed.) Approaches to Organizational Design, Pittsburgh: Pittsburgh University Press, pp.173-188.

Faith, N. (2002) Liquid Gold, Sydney: MacMillan, pp.394-411.

Freeman, J.H. and Audia, P.G. (2006) 'Community ecology and the sociology of organizations', Annual Review of Sociology, Vol. 32, pp.145-169.

Grape and Wine Research and Development Corporation (GWRDC) (2004) Annual Report, pp.215. 
Grape and Wine Research and Development Corporation (GWRDC) (2005) Annual Report, www.gwrdc.com.au/publications.asp.

Hannan, M.T. and Freeman, J. (1984) 'Structural inertia and organizational change', American Sociological Review, Vol. 49, pp.149-160.

Hannan, M.T. and Freeman, J. (1989) Organizational Ecology, Cambridge: Harvard University Press.

Hannan, M.T., Polos, L. and Carroll, G.R. (2004) 'Cascading organizational change’, Organization Science, Vol. 14, pp.463-482.

Henry, P. (2006) 'Industry needs creative ideas’, Wine Business Monthly, September, pp.26-29.

Johnson, H. (2006) Wine: A Life Uncorked, London: Weidenfeld \& Nicolson, pp.16, 35-45, 259-280.

Lockshin, L. (2006) 'What’s our plan for trading up?', Wine Business Magazine, Adelaide, pp.6365.

MacQuitty, J. (2006) 'Aussies lacking a middle order: Australian wine’s quest for regionality has not persuaded us to pay more for it', Timesonline.

Margan, A. (2006) 'Industry needs creative ideas’, Wine Business Monthly, September, pp.26-29.

Narula, R. and Zanfei, A. (2005) 'Globalization of innovation: the role of multinational enterprises', in J. Fagerberg, D.C. Mowery and R.R. Nelson (Eds.) The Oxford Handbook of Innovation, Oxford: Oxford University Press, pp.318-345.

Pfeffer, J. and Salancik, G.R. (1978) The External Control of Organizations: A Resource Dependence Perspective, New York: Harper and Row.

Pirie, A. (2006) Wine Business Monthly, September, pp.24-26.

Ruef, M. (2004) 'For whom the bell tolls: ecological perspectives on industrial decline and resurgence', Industrial and Corporate Change, Vol. 13, No. 1, pp.61-89.

Sanders, M. (2005) Families of the Vine, London: Bantam Books, pp.129-135.

Sands, R. (2006) Constellation Annual Report, New York, pp.2-16.

Singh, J.V. and Lumsden, C.J. (1990) 'Theory and research in organizational ecology', Annual Review of Sociology, Vol. 16, pp.161-195.

Smart, C. (2006) 'Industry needs creative ideas’, Wine Business Monthly, September, pp.26-29.

Smart, R. (2005) 'Grape and wine research: what is next?', The Australian and New Zealand Wine Industry Journal, Vol. 20, No. 6, pp.14-16.

Steinberger, M. (2004) The Winding Alleyways of St Emilion, 15 April, http://fray.slate.com/id/ 2098622/entry/2098905.

Trist, E.L. (1977) 'A concept of organizational ecology', Australian Journal of Management, Vol. 2, pp.161-175.

Trist, E.L. (1983) 'Referent organizations and the development of interorganizational domains', Human Relations, Vol. 36, pp.269-284.

Visser, E-J. (2003) 'A Chilean wine cluster?’, The Quality and Importance of Local Governance in a Fast Growing and Internationalizing Industry, Department of Economic Geography, Utrech University, the Netherlands, pp.3-15.

Whetten, D.A. (1981) 'Interorganizational relations: a review of the field', Journal of Higher Education, Vol. 52, pp.1-27.

Winetitles (2005) Australian and New Zealand Wine Industry Directory, Adelaide, pp.1-15. 